\title{
Classification of White Cultivar Wines by Origin using Volatile Aroma Components
}

\author{
J. MARAIS, P. C. VAN ROOYEN and C. S. DU PLESSIS \\ Oenological and Viticultural Research Institute, Private Bag X5026, Stellenbosch, 7600
}

\begin{abstract}
Stepwise discriminant analysis was applied to gas chromatographic data of some volatile compounds obtained by freon extraction of dry white table wines. By means of this statistical method, successful classifications according to origin of Colombar wines from two regions, and Chenin blanc wines from three regions, were obtained. The components with the highest discriminatory value were $\mathrm{i}$-amyl acetate, hexyl acetate and i-butanol, in the case of the Colombar wines and hexanol and 2-phenyl ethanol in the case of the Chenin blanc wines.
\end{abstract}

The quality of a wine is attributed to an integrated response of many individual constituents, some originating in the grapes, and others produced during fermentation. Gas chromatography allows the analysis of so large a number of volatiles that visual interpretation of these data becomes very difficult and in many cases almost impossible. The reduction of the normally large number of variables to facilitate meaningful interpretation has become a major task for oenologists. In an attempt to select the most important components with respect to wine quality, various statistical methods have been employed in recent years.

The classification of wines according to origin, grape cultivar and vintage year has been carried out successfully by the application of multivariate statistical techniques. Pattern recognition techniques have been applied to the trace element composition (Siegmund \& Bächmann, 1978; Kwan, Kowalski \& Skogerboe, 1979), and to the volatile composition of wines (Kwan \& Kowalski, 1978; Kwan \& Kowalski, 1980). Stepwise discriminant analysis has been applied to terpene compounds in grapes (Sciureier et al. 1976; Rapp et al. 1978), to the volatile composition of wines (Marais, Van Rooyen \& Du Plessis, 1981) and to headspace volatiles of wines at equilibrium concentrations (Noble, Flath \& Forrey, 1980).

The aim of this study was firstly, to select key components, mainly fermentation-produced flavour compounds, which relate to the geographic origins of the wines, and secondly, to direct further investigations into the selection and identification of wine quality parameters in order to relate chemical composition of wine to sensory quality. The study was performed on two commonly cultivated white wine cultivars in South Africa, viz. Chenin blanc and Colombar.

\section{MATERIALS AND METHODS}

Twenty-two dry white wines of the Colombar cultivar from the Robertson and Lutzville areas, as well as 38 dry white wines of the Chenin blanc cultivar from the Stellenbosch, Robertson and Lutzville areas were used in this study. Stellenbosch is a relatively cool agricultural region, while Robertson (dry, hot) and Lutzville (desert, very hot) are dependent upon irrigation for grape production. All the wines were of the 1979 vintage.
Grapes in various stages of ripeness were harvested periodically over approximately six weeks from the same vineyards to induce variations in quality. The sugar content of the grapes varied between approximately $19^{\circ} \mathrm{B}$ to $23^{\circ} \mathrm{B}$. The wines were made using standard techniques employed at the experimental cellar of the OVRI.

The wines were extracted with freon and analyzed quantitatively for esters and higher alcohols by means of gas chromatography (Marais \& Houtman, 1979) on a Hewlett Packard 5840 A gas chromatograph fitted with an automatic peak integrator. To limit possible effects of time on wine composition, all samples were analyzed within one month.

The BMD07M computer program (Dixon, 1974) was utilized, performing a stepwise multiple discriminant analysis (SDA).

\section{RESULTS AND DISCUSSION}

The components analyzed, as well as their average concentrations for the Colombar and Chenin blanc wines, are given in Table 1.

The components (variables) were classified into three Sets viz. (1) four higher alcohols, (2) eight esters and (3) the total of the first two Sets plus two acids (See Table 1). Data processing was executed on a Burroughs 7700 computer, discriminating amongst wines of the same cultivar originating from the different wine regions.

Colombar: SDA was applied to data from wines from two regions, viz. 10 and 12 wines from the Robertson and Lutzville areas respectively. The most successful separations were obtained when employing the variables in Sets 2 and 3 . The discriminant variables in decreasing order of importance for each Set as selected by SDA are given in Table 2 .

In both cases it was found that i-amyl acetate was the most effective discriminant. Although a classification employing Set 1 (higher alcohols) (Fig. 1a) was relatively unsuccessful, i-butanol emerged as the second most important discriminant when Set 3 (Fig. 1c) was implemented. Canonical plots of the separations of the wines from two regions employing Sets 1,2 and 3 are shown in Figures 1(a), (b) and (c) respectively. 
TABLE 1.

Average concentrations of esters, higher alcohols and acids of Colombar and Chenin blanc wines from different regions (1979 vintage).

\begin{tabular}{|c|c|c|c|c|c|}
\hline \multirow{2}{*}{ Components $(\mathrm{mg} / \ell)$} & \multicolumn{2}{|c|}{ Colombar } & \multicolumn{3}{|c|}{ Chenin Blanc } \\
\hline & Robertson & Lutzville & Stellenbosch & Robertson & Lutzville \\
\hline \multicolumn{6}{|l|}{ Esters } \\
\hline Ethyl acetate ... & 39,26 & 44,55 & 46,02 & 44,23 & 48,30 \\
\hline Ethyl butyrate $\ldots \ldots \ldots \ldots \ldots \ldots \ldots$ & 0,40 & 0,54 & 0,61 & 0,52 & 0,55 \\
\hline i-Amyl acetate $\ldots \ldots \ldots \ldots \ldots \ldots \ldots$ & 2,90 & 4,37 & 2,67 & 2,39 & 2,52 \\
\hline Ethyl caproate $\ldots \ldots \ldots \ldots \ldots \ldots \ldots$ & 0,75 & 0,92 & 0,84 & 0,84 & 0,83 \\
\hline Hexyl acetate $\ldots \ldots \ldots \ldots \ldots \ldots \ldots$ & 0,16 & 0,19 & 0,13 & 0,09 & 0,14 \\
\hline Ethyl caprylate $\ldots \ldots \ldots \ldots \ldots \ldots \ldots$ & 1,35 & 1,53 & 1,41 & 1,50 & 1,55 \\
\hline Ethyl caprate.$\ldots \ldots \ldots \ldots \ldots \ldots \ldots$ & 0,39 & 0,40 & 0,27 & 0,32 & 0,29 \\
\hline 2-Phenethyl acetate $\ldots \ldots \ldots \ldots \ldots \ldots$ & 0,15 & 0,18 & 0,13 & 0,15 & 0,14 \\
\hline \multicolumn{6}{|l|}{ Higher Alcohols } \\
\hline i-Butanol $\ldots . .$. & 24,28 & 26,02 & 26,20 & 26,94 & 28,42 \\
\hline Amyl alcohols . & 169,71 & 157,71 & 139,86 & 162,46 & 147,95 \\
\hline Hexanol ........... & 1,07 & 1,08 & 1,04 & 1,36 & 0,93 \\
\hline 2-Phenyl ethanol $\ldots \ldots \ldots \ldots \ldots \ldots \ldots$ & 20,31 & 15,39 & 11,45 & 17,31 & 15,75 \\
\hline \multicolumn{6}{|l|}{ Acids } \\
\hline Hexanoic acid $\ldots \ldots \ldots \ldots \ldots \ldots \ldots$ & 5,49 & 7,22 & 6,13 & 5,86 & 5,88 \\
\hline Octanoic acid $\ldots \ldots \ldots \ldots \ldots \ldots \ldots$ & 6,88 & 8,01 & 7,72 & 7,23 & 7,14 \\
\hline
\end{tabular}

TABLE 2 .

Significance of discriminant variables for the classification of 22 Colombar wines into two regions employing Set 2 (esters) and Set 3 (esters + higher alcohols + acids).

\begin{tabular}{|c|c|c|c|}
\hline \multicolumn{2}{|l|}{ SET 2} & \multicolumn{2}{|l|}{ SET 3} \\
\hline Variable Entered & F-value to Enter & Variable Entered & F-value to Enter \\
\hline 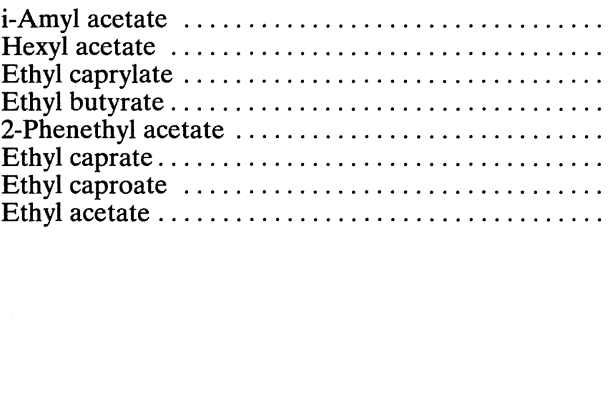 & $\begin{array}{r}20,14^{* *} \\
10,93^{* *} \\
5,96^{* *} \\
2,21 \mathrm{~ns} \\
1,80 \mathrm{~ns} \\
0,93 \mathrm{~ns} \\
0,22 \mathrm{~ns} \\
0,01 \mathrm{~ns}\end{array}$ & 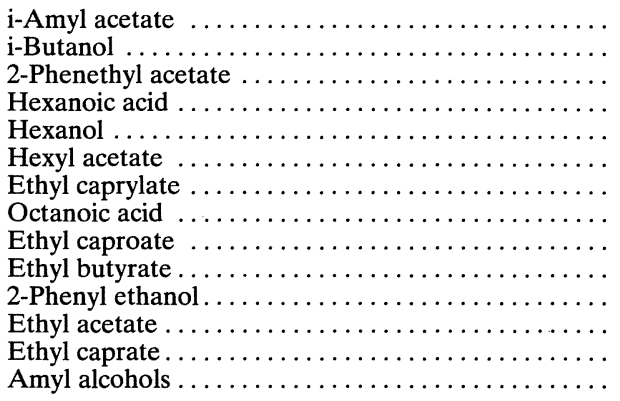 & $\begin{array}{l}20,14^{* *} \\
13,11^{* *} \\
7,90^{* *} \\
7,27^{* *} \\
6,49^{* *} \\
6,13^{*} \\
5,02^{*} \\
3,92^{*} \\
2,77 \mathrm{~ns} \\
2,67 \mathrm{~ns} \\
2,05 \mathrm{~ns} \\
1,92 \mathrm{~ns} \\
1,83 \mathrm{~ns} \\
0,38 \mathrm{~ns}\end{array}$ \\
\hline
\end{tabular}

$\begin{aligned} * * & =\text { Highly significant at } \mathrm{P} \leqslant 0,01 . \\ * & =\text { Significant at } \mathrm{P} \leqslant 0,05 .\end{aligned}$

ns $=$ Not significant.

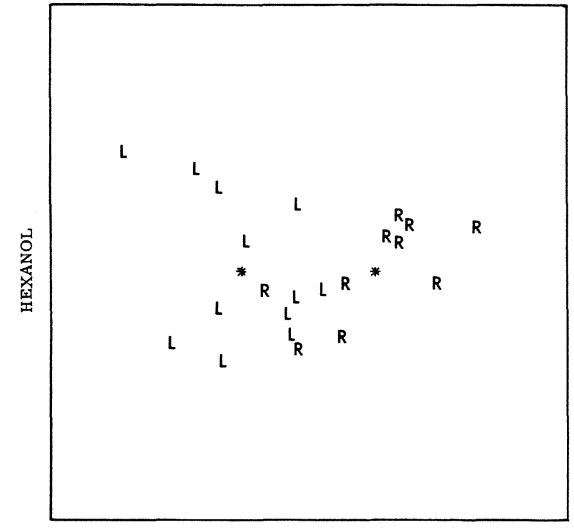

2-PHENYL ETHANOL

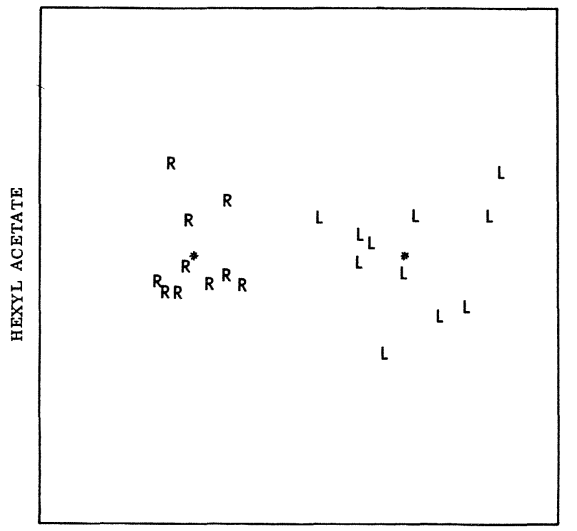

i-AMYL ACETATE

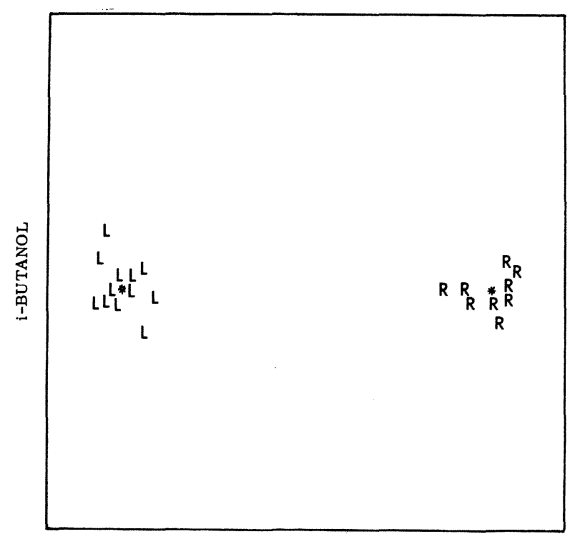

i-AMYL ACETATE

$\mathrm{R}=$ Robertson

$\mathrm{L}=$ Lutzville

${ }^{*}=$ Mathematical centre of each group.

FIG. 1

A canonical plot showing separation of Colombar wines from Robertson and Lutzville areas on the basis of (a) four higher alcohols, (b) eight esters and (c) four higher alcohols, eight esters and two acids (1979 vintage).

S. Afr. J. Enol. Vitic., Vol. 2. No. 2. 1981 
From both Figures 1(b) and (c) it can be seen that i-amyl acetate was by far the most powerful discriminant between regions, while the other variables were not able to separate the groups on their respective axes. It is noteworthy that i-amyl acetate also emerged as the most effective component in the differentiation between the wines of Pinotage and Cabernet sauvignon cultivars in a previous study (Marais, Van Rooyen \& Du Plessis, 1981). It is reasonable to conclude that this compound is a relatively sensitive parameter, at least under the conditions of these experiments. Similarly, the findings of Houtman \& Du Plessis (1981) noted the importance of acetate esters as sensitive indicators with respect to fermentation conditions. Ester formation is dependent upon inter alia a supply of alcohols and acids and the formation of acyl-CoA-compounds (Nordström, 1964; Nordström, 1966). All the acetate esters and their corresponding higher alcohols, except hexyl acetate, are produced during amino acid metabolism by the Ehrlich-mechanism, as well as during amino acid synthesis by enzymatic reactions in the course of fermentation. The alcohol moiety of i-amyl acetate derives from the de-amination of leucine which, depending upon its availability, could lead to differences in the concentration of this ester in wines. However, the formation of esters, and specifically i-amyl acetate, is an extremely complex process. It is also affected by factors other than specific amino acid concentrations. Consequently, it is difficult at this stage to ascribe the significant variations in i-amyl acetate concentrations between Colombar wines of different regions to one specific factor. This aspect certainly requires further study. Hexyl acetate formation is more dependent on the six-carbon precursors present in the juice (Drawert \& Rapp, 1966).

It has been reported that variations in specific ester concentrations within a series of wines of a cultivar are often as great as amongst different cultivar wines (Houtman, Marais \& Du Plessis, 1980; Noble, Flath \& Forrey, 1980). Furthermore, it has been shown that different fermentation temperatures of the same must could produce variations in ester concentrations (Kilian \& Ough, 1979).

As mentioned earlier, fermentation conditions for all the wines were identical in this study, but it is important to note that in the case of esters which are sensitive to cellar manipulations, results from discriminant analysis should be employed with caution.

Chenin blanc: By employing the same three Sets of variables as in the case of the Colombar wines, the most successful separations of Chenin blanc wines from Stellenbosch (16 wines), Robertson (12 wines) and Lutzville (10 wines) regions were obtained with Sets 1 and 3 . In both cases hexanol and 2-phenyl ethanol were selected as the most important discriminants. The discriminant variables in decreasing order of importance for each Set are given in Table 3.

Employing only the esters in Set 2, successful classifications could not be obtained. Canonical plots of the classifications employing Sets 1, 2 and 3 are presented in Figures 2(a), (b) and (c) respectively.

From Figures 2(a) and (c) it can be seen that as a discriminant hexanol was reasonably successful in discriminating among the wines from the three regions (Fig. 2(c)), but that 2-phenyl ethanol had no utility as discriminant between the Chenin blanc wines from the Robertson and Stellenbosch areas. The less obvious discriminatory power of the same variables when employed in Set 1 (Fig. 2(a)), illustrates the importance of the additional variables in the case of Set 3. They contribute to a significant extent to the reduction of uncertainty in the separations.

In an earlier similar study of Pinotage and Cabernet sauvignon red wines, hexanol was also selected as the most effective discriminatory variable in the differentiation between the two cultivars when only four higher alcohols were employed (Marais, Van Rooyen \& Du Plessis, 1981).

TABLE 3

Significance of discriminant variables for the classification of 38 Chenin blanc wines into three regions employing Set 1 (higher alcohols) and Set 3 (esters + higher alcohols + acids).

\begin{tabular}{|c|c|c|c|}
\hline \multicolumn{2}{|l|}{ SET 1} & \multicolumn{2}{|l|}{ SET 3} \\
\hline Variable Entered & F-value to Enter & Variable Entered & F-value to Enter \\
\hline 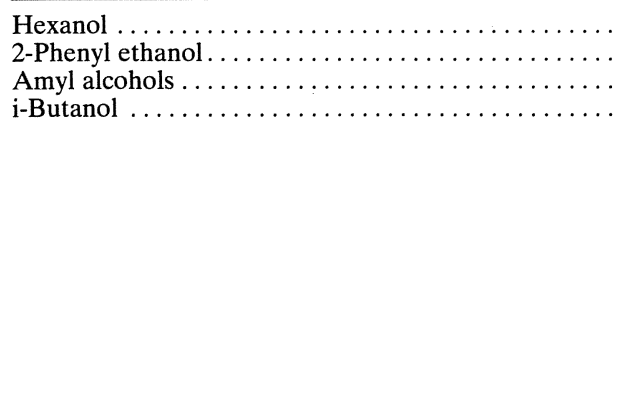 & $\begin{array}{l}24,11^{* *} \\
19,04^{* *} \\
14,40^{* *} \\
10,64^{* *}\end{array}$ & 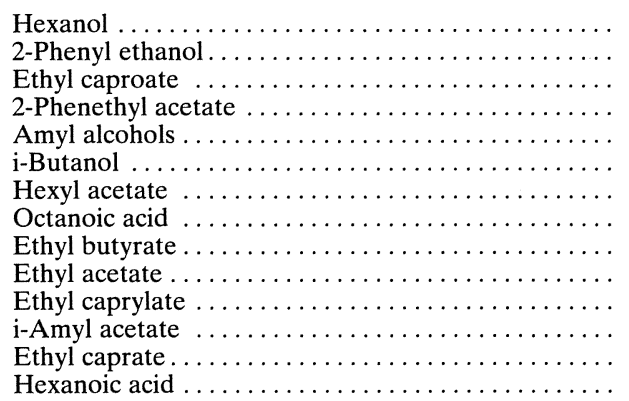 & $\begin{array}{r}24,11^{* *} \\
19,04^{* *} \\
18,64^{* *} \\
14,84^{* *} \\
14,40^{* *} \\
10,64^{* *} \\
6,35^{* *} \\
6,19^{* *} \\
4,75^{* *} \\
4,38^{* *} \\
3,55^{* *} \\
1,75 \mathrm{~ns} \\
0,82 \mathrm{~ns} \\
0,32 \mathrm{~ns}\end{array}$ \\
\hline
\end{tabular}

** = Highly significant at $\mathrm{P} \leqslant 0,01$.

$\mathrm{ns}=$ Not significant . 


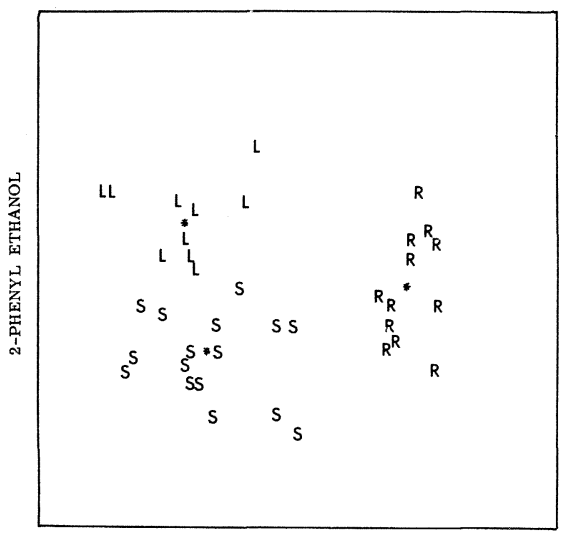

HEXANOL

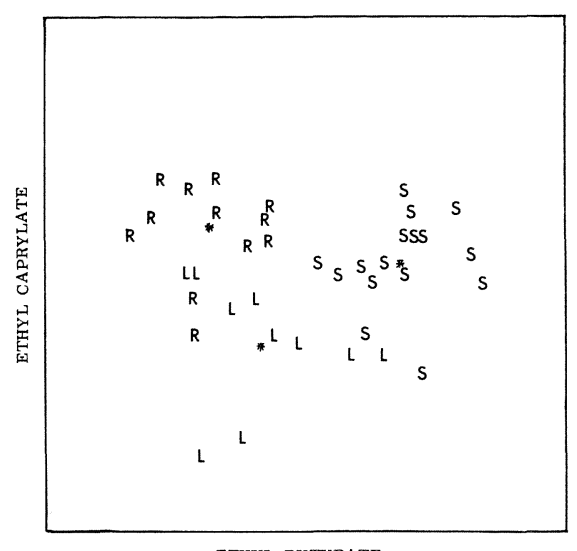

ETHYL BUTYRATE

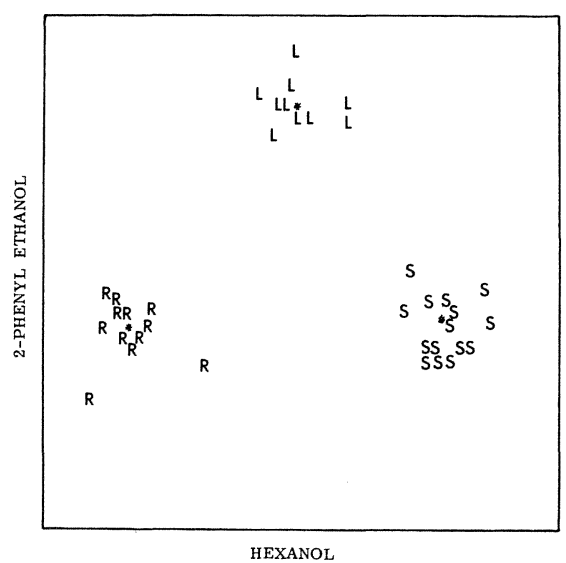

HEXANOL

FIG. 2

A canonical plot showing separation of Chenin blanc wines from Stellenbosch, Robertson and Lutzville areas on the basis of (a) four higher alcohols, (b) eight esters and (c) four higher alcohols, eight esters and two acids (1979 vintage).

$\mathrm{S}=$ Stellenbosch

$\mathrm{R}=$ Robertson

$\mathrm{L}=$ Lutzville

* = Mathematical centre of each group.

Kwan \& Kowalski (1980) similarly reported that hexanol was one of the two most important components in the classification of French and American Pinot noir wines, while 2-phenyl ethanol was one of the major distinguishing components between Californian Pinot noir wines and those produced in the Pacific North-west region.

Hexanol derives from linoleic and linolenic acids, which are likely constituents of the waxy bloom covering the skin of the grape berry (Brander, Kepner \& Webb, 1980). Skin/juice contact as well as differences in the concentrations of these acids amongst cultivars, or within a specific cultivar from different localities, could produce differences in the concentrations of hexanol in the wines. In this study both Chenin blanc and Colombar grapes received the same free-run treatment. 2-Phenyl ethanol, which was also the second most important component in the differentiation between Chenin blanc wines of the three regions (Table 3), derives via the Ehrlichmechanism from the amino acid phenyl alanine. As in the case of the Colombar wines, a study of the amino acids should be incorporated to determine whether they can be related to regional differences.

With reference to the contribution of the selected compounds to the flavour of wine, odour threshold values could possibly provide some useful information. Odour threshold values (ppm) as determined in a specially prepared wine residue medium by De Wet et al. (1978), revealed values of 0,16 and 0,64 for i-amyl acetate and optically active amyl acetate respectively. The two components were not gas chromatographically separated, and were analyzed as one component viz. i-amyl acetate, which normally amounts to approximately $90 \%$ of the total amount of amyl acetates. Compared to i-amyl acetate concentrations in Table 1 , it seems reasonable to assume that this fermentation-produced compound contributes significantly to wine quality, especially to the bouquet of young wine. This corresponds with research reported on this aspect of wine quality by Marais \& Pool (1980), who found highly significant correlations between i-amyl acetate concentrations and young wine bouquet. Other available odour threshold values are 0,67 (hexyl acetate), 227,90 (i-butanol) and 1,08 (hexanol). It is clear that i-butanol concentrations (Table 1 ) are much too low to make a significant contribution to wine flavour.

It is important to note that the regional classifications were achieved by using wines from grapes at different stages of maturity. It appears, therefore, that the effect of this factor is relatively insignificant in relation to that of the region. Similarly Rapp et al. (1978) found that differentiation of Riesling and Morio Muscat grapes was possible, and that this was independent of stage of ripeness. The three regions involved in this study, have fairly different climatic conditions viz. the relatively cool Stellenbosch area, where viticulture can be practised without irrigation, the relatively dry, hot Robertson area, and the desertlike conditions in the Lutzville area.

\section{CONCLUSIONS}

As in the case of red wine cultivars (Marais, Van Rooyen \& Du Plessis, 1981), highly successful regional classifications of wines made from the white wine cultivars Colombar and Chenin blanc were obtained by application of SDA. These classifications could be made by using relatively few fermentation-produced flavour compounds.

The value of multivariate analysis has far-reaching possibilities. Apart from its use in geographical classification or cultivar identification, it also opens promising fields of investigation with regard to wine quality and character parameters. More should be learned of the 
contributions of such factors as cultivar, regional and climatic conditions, as well as viticultural and cellar technological practices which are normally reflected in the chemical composition of the wines. The coupling of discriminatory components such as i-amyl acetate in the case of Colombar, and hexanol in the case of Chenin blanc wines, as well as their formation mechanisms, to wine quality, is a distinct possibility.

\section{LITERATURE CITED}

BRANDER, C. F., KEPNER, R. E. \& WEBB, A. D., 1980. Identification of some volatile compounds of wine of Vitis vinifera cultivar Pinot noir. Am. J. Enol. Vitic. 31, 69-75.

DE WET, P., AUGUSTYN, O. P. H., VAN WYK, C. J. \& JOUBERT, W. A., 1978. Odour thresholds and their application to wine flavour studies. Proc. S. Afr. Soc. Enol. Vitic., Symp. Cape Town, Oct., 28-42.

DIXON, W. J., Ed., 1974. Biomedical Computer Programs, University of California Press, Berkeley, CA.

DRAWERT, F: \& RAPP, A., 1966. Über Inhaltsstoffe von Mosten und Weinen. VII Gaschromatographische Untersuchung der Aromastoffe des Weines und ihrer Biogenese. Vitis 5, 351-376.

HOUTMAN, A. C., MARAIS, J. \& DU PLESSIS, C. S., 1980. The possibilities of applying present-day knowledge of wine aroma components: Influence of several juice factors on fermentation rate and ester production during fermentation. S. Afr. J. Enol. Vitic. 1, 27-33.

HOUTMAN, A. C. \& DU PLESSIS, C. S., 1981. The effect of juice clarity and several yeast growth promoting conditions on fermentation rate, the production of aroma components and wine quality. S. Afr. J. Enol. Vitic. 2, 71-81.

KILIAN, E. \& OUGH, C. S., 1979. Fermentation estersformation and retention as affected by fermentation temperature. Am. J. Enol. Vitic. 30, 301-305.

KWAN, W. O. \& KOWALSKI, B. R., 1978. Classification of wines by applying pattern recognition to chemical composition data. J. Food Sci. 43, 1320-1323.
KWAN, W. O., KOWALSKI, B. R. \& SKOGERBOE, R. K., 1979. Pattern recognition analysis of elemental data. Wines of Vitis vinifera cv. Pinot noir from France and the United States. J. Agric. Food Chem. 27, 1321-1326.

KWAN, W. O. \& KOWALSKI, B. R., 1980. Pattern recognition analysis of gas chromatographic data. Geographic classification of wines of Vitis vinifera cv. Pinot noir from France and the United States. J. Agric. Food Chem. 28, 356-359.

MARAIS, J. \& HOUTMAN, A. C., 1979. Quantitative gas chromatographic determination of specific esters and higher alcohols in wine using freon extraction. Am. J. Enol. Vitic. 30, 250-252.

MARAIS, J. \& POOL, H. J., 1980. Effect of storage time and temperature on the volatile composition and quality of dry white table wines. Vitis 19, 151-164.

MARAIS, J., VAN ROOYEN, P. C. \& DU PLESSIS, C. S., 1981. Differentiation between wines originating from different red wine cultivars and wine regions by the application of stepwise discriminant analysis to gas chromatographic data. S. Afr. J. Enol. Vitic. 2, 19-23.

NOBLE, ANN C., FLATH, R. A. \& FORREY, R. R., 1980. Wine headspace analysis. Reproducibility and application to varietal classification. J. Agric. Food Chem. 28, 346-353.

NORDSTRÖM, K., 1964. Studies on the formation of volatile esters in fermentation with Brewer's Yeast. Svensk Kem. Tidskr. 76, 9-43.

NORDSTRÖM, K., 1966. Formation of esters from lower fatty acids by various yeast species. J. Inst. Brew. 72, 38-40.

RAPP, A., HASTRICH, H., ENGEL, L. \& KNIPSER, W., 1978. "Flavor of foods and beverages." Possibilities of characterizing wine quality and vine varieties by means of capillary chromatography. Academic Press, N.Y., S.F., Lond. 391-417.

SCHREIER, P., DRAWERT, F., JUNKER, A. \& REINER, L., 1976. Anwendung der multiplen Diskriminanzanalyse zur Differenzierung von Rebsorten an Hand der quantitativen Verteilung flüchtiger Weininhaltsstoffe. Mitt. Klosterneuburg 26, 225-234.

SIEGMUND, H. \& BÄCHMANN, K., 1978. Anwendung der numerischen Taxonomie für die Klassifizierung von Weinen. Z. Lebensm.-Unters.-Forsch. 166, 298-303. 